\title{
Numerical Analysis on Parameters Adjustment of Smoke Control System in a Complicated Underground Commercial Zone
}

\author{
Dewen LI, Jingzhao ZHANG \\ School of energy engineering, Xi'an University of Science and Technology, Xi'an, Shaanxi, China \\ zhangjz98@126.com
}

Keywords: Parameter adjustment, Underground commercial zone, Smoke control system, Evacuation time.

\begin{abstract}
The technical parameters adjustment of smoke control system in a complicated underground commercial zone is studied by numerical simulations. An underground fire model (it encloses a hotel, a supermarket, and a net bar) and five typical fire scenarios are designed. The Fire Dynamic Simulator code is used to investigate the characteristics of fire spread and smoke movement, and obtain the available safety egress times in different fire scenarios. The required safety egress time is calculated based on the data of actual simulation exercises and numerical simulation by Building EXODUS. The simulation results show that, when the smoke exhaust rate is 5.56 cubic meter per second and air low rate reaches 3.89 cubic meter per second simultaneously, the available safety egress time is more than the required safety egress time.
\end{abstract}

\section{Introduction}

In various forms of underground constructions, underground commerce zone (especially when it nears the railway station) has a higher fire risk, because of the particularity of the more combustible substance, the large fire-loads, personnel-intensive, the personnel evacuation difficulty, etc. Once a fire occurs in the underground commerce zone, it easily results in the heavy casualties and the enormous property loss. In the four years range from 2000 to 2003, the number of accidents, deaths and economic losses caused by underground buildings fire in China are 7673, 924 and 17.2 million RMB, respectively [1].

In an underground fire, high temperatures and smoke concentration provide conditions where the chance of survival is near zero [2]. The fire smoke was suggested the major threat for the people trapped underground, as it spreads rapidly throughout the area, reducing the visibility and causing deaths due to the hazardous gases [3]. Thus, the most important action should focus on controlling the propagation of fire smoke by means of sprinklers and smoke control systems in a fire [3-5].

For underground commerce zone, the effect of smoke control is worth discussing due to high test cost though codes provide design principles about smoke exhaust in China [6].

The underground commerce zone in Xi'an(China) railway station square (hereinafter referred to as underground commerce zone) was built in 1985. Nowadays, its ventilation and smoke exhaust systems cannot meet the requirement of emergency situation anymore because of the increased dramatically passenger volume. This paper presents the parameters adjustment scheme of smoke control system by numerical simulation, which provide the necessary control of smoke and heated gases within a complicated underground zone (including a hotel, a net bar, and a supermarket), if a fire occurs.

\section{Critical Parameters and Evacuation Times}

Critical Parameters. Critical parameters are the critical environmental parameters in fire which human are almost unbearable, and it containing the height of the smoke layer, personnel security visibility, concentration of toxic gases and the temperature of fire smoke.

According to [7] and [8], the critical parameters which can ensure personnel safety evacuation are showed in Table 1. As the complexity of underground commerce zone (e.g. bad light, obstacles in the 
hotel corridor, etc), expect the critical smoke temperature, the additional assurance factors were used to amend the critical parameters in the present work as shown in Table 1.

Table 1. Critical parameters of personnel safety evacuation in fire

\begin{tabular}{lcccc}
\hline \multicolumn{1}{c}{ Items } & $\begin{array}{c}\text { Smoke layer } \\
\text { height[m] }\end{array}$ & Temperature[K] & $\begin{array}{c}\text { CO } \\
\text { concentration[ppm] }\end{array}$ & Visibility[m] \\
\hline [7] and [8] & $>1.5$ & $<333$ & $<1000$ & $>5$ \\
Present work & 2 & 333 & 500 & 10 \\
\hline
\end{tabular}

Some researches show that people's tolerance time in 71 degree Celsius and normal humidity is 3600 seconds, while 720 seconds in 60 degree Celsius and saturated humidity condition[9]. The critical smoke temperature is set to 333 Kelvin because the safe passage of the underground commerce zone in this paper is not too long.

Evacuation Times. In case of a fire, available safety egress time $\left(\mathrm{T}_{\mathrm{A}}\right)$ and required safety egress time $\left(T_{R}\right)$ are the two key factors which were used to estimate whether personnel can evacuate safely or not [10]. Personnel can evacuate safely when $\mathrm{T}_{\mathrm{R}}<\mathrm{T}_{\mathrm{A}}$.

Based on the critical parameters of Table $1, \mathrm{~T}_{\mathrm{A}}$ will be obtained through simulating the movement characteristics of the fire smoke under the sprinklers and smoke control systems in underground commerce zone by Fire Dynamic Simulator (FDS, Ver5.5). TR encloses fire detection and alarm time $\left(\mathrm{T}_{\text {ALARM }}\right)$, evacuation preparation time $\left(\mathrm{T}_{\text {PREPARATION }}\right)$ and evacuation action time $\left(\mathrm{T}_{\text {ACTION }}\right)[11]$.

In the actual evacuation, evacuation action time may longer than the case of ideal condition under the influence of some unfavorable factors, such as peoples are not familiar with the buildings, personnel vigilance is poor, safety evacuation indicators are not clear, and simulation conditions are not accurate enough, etc. The hotel guests in underground commerce zone are almost tired and not familiar with the subsurface structure because they are outsiders. Therefore, it is necessary to consider an additional safety coefficient to increase the evacuation action time. The additional safety coefficient, 1.5, was used in present work.

$\mathrm{T}_{\mathrm{R}}=\mathrm{T}_{\text {ALARM }}+\mathrm{T}_{\text {PREPARATION }}+1.5 \times \mathrm{T}_{\text {ACTION }}$.

(1)

\section{Fire Scenario Design}

Computation Model. Underground commerce zone is composed of the underground plaza, the western underground commerce zone, the eastern underground commerce zone, and the southern underground commerce zone. The underground plaza is a square in the open air containing small shops, restaurants and teahouses, etc. The southern underground commerce zone consists of hotels and an underground parking, while the western and the eastern underground commerce zones enclose small shops, hotels, supermarkets, and net bars.

Owing to the structural complexity of the underground commerce zone, a local region in the western underground commerce zone is chosen as the research region which encloses a hotel, a supermarket, and a net bar in present work.

Through the field survey, it is found that most of the hotel clients are sleeping even during the day. Therefore, the ignition source was set in a single-room of the hotel near the fire exit. Fig. 1 shows the computation model and the ignition source position.

Heat Release Rate. Because there have the sprinklers and smoke control systems in the research region, an unsteady fire model is designed which include a growth phase and a steady phase. When designing the growth phase of the fire, t-squared fire growth model [8] is the most common method.

According to the definition of the fire growth factor in [8], the fire growth factor is taken the value of 0.047 in consideration of the actual complex situation of the computation model. Similarly, the maximum heat release rate is 6.0 million watt when the sprinklers and smoke control system in failure condition, while 1.5 million watt in normal conditions which are assumed that the sprinklers just can control the fire. 


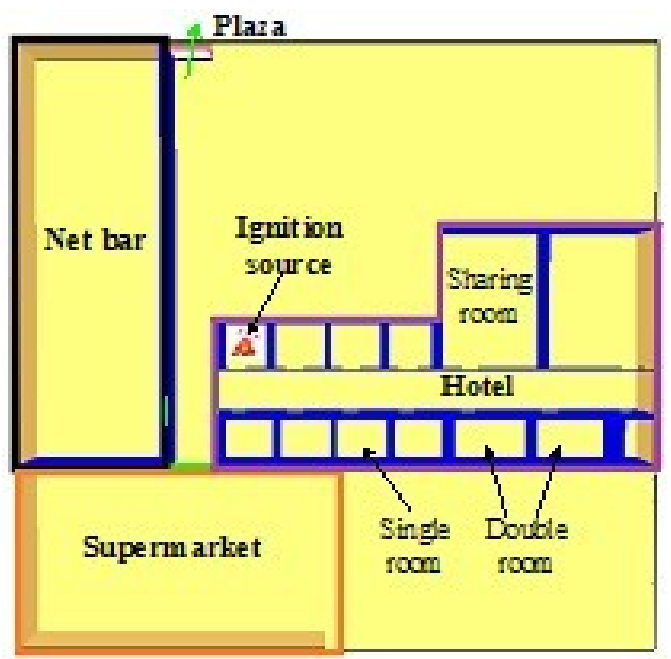

Fig. 1 Computation model.

Smoke Control System. There are three $1 \mathrm{~m} \times 0.4 \mathrm{~m}$ smoke outlets in computation model which are set in center of the net bar's ceiling, center of the supermarket's ceiling, and the center top of the hotel corridor, respectively. Besides, there also have three $0.6 \mathrm{~m} \times 0.5 \mathrm{~m}$ secondary tuyeres under the store smoke warehouses in the computation model.

According to [8], the minimum smoke exhaust rate of each smoke outlet is 13000 cubic meter per hour, and the air flow rate of the secondary tuyere is not less than 50 percent of the smoke exhaust rate. Through the field test, it is found that the smoke control system of underground commerce zone cannot meet the provision of the regulations owing to the outdated design.

Fire Scenarios. In order to adjust the smoke control system, five typical fire scenarios of the computation model were designed which are shown in Table 2.

Table 2. Fire Scenarios

\begin{tabular}{cccc}
\hline Case & Q[W] & Smoke exhaust rate $\left[\mathrm{m}^{3} \cdot \mathrm{s}^{-1}\right]$ & Air flow rate $\left[\mathrm{m}^{3} \cdot \mathrm{s}^{-1}\right]$ \\
\hline 1 & 6000000 & 0 & 0 \\
2 & 1500000 & 3.89 & 1.94 \\
3 & 1500000 & 3.89 & 2.72 \\
4 & 1500000 & 5.56 & 2.78 \\
5 & 1500000 & 5.56 & 3.89 \\
\hline
\end{tabular}

In addition, all the five Cases in Table 2 have the same ignition source position (see Fig.1), fire growth factor (0.047) in the growth phase of the fire, and Case 2-5 also have the same smoke outlets and secondary tuyeres which were introduced in Smoke Control System.

Case 1 is the most unfavorable conditions whose sprinklers and smoke control systems are all failure while other Cases are normal. The maximum heat release rates of Case 2-5 are equal to 1.5 million watt in steady phase of the fire because of the normal sprinklers system, and the different smoke exhaust rates and air flow rates were designed to estimate the necessary technical parameters of the smoke control system in the computation model.

\section{Numerical Simulation}

Prediction of the Available Safety Egress Times. Fire dynamics simulator code was used to simulate the process of the smoke flow and heat transfer in the five fire scenarios in order to obtaining the available safety egress times according to the critical parameters in Table 1.

Simulation results are shown in Table 3. It is important to note that TTEMPERATURE in Table 3 is the time which the temperature of 2 meters height positions reaches 333 Kelvin, and TVISIBILITY is the time which the visibility of 2 meters height positions down to 10 meters, while TA is the smaller one; $\mathrm{CO}$ concentrations are smaller than the critical value in Table 1 except Case 1.

Table 3. Simulation Results of Available Safety Egress Time. 


\begin{tabular}{cccc}
\hline Case & $\mathrm{T}_{\text {TEMPERATURE }}[\mathrm{s}]$ & $\mathrm{T}_{\text {VISIBILITY }}[\mathrm{s}]$ & $\mathrm{T}_{\mathrm{A}}[\mathrm{s}]$ \\
\hline 1 & 130 & 150 & 130 \\
2 & 165 & 190 & 165 \\
3 & 190 & 200 & 190 \\
4 & 220 & 220 & 220 \\
5 & 250 & 245 & 245 \\
\hline
\end{tabular}

Analyzing the data in Table 3, it is found that the critical temperature is the major factor which almost determining all the available safety egress times, and the sprinklers and smoke control systems plays a significant role in safety evacuation, the system in Case 5 provides almost twice as many than the safe evacuation time in Case 1. Besides, 25 seconds were saved (in Case 3 or Case 5) through increasing the air flow rate of secondary tuyeres.

With Case 1 as an example, simulation results of smoke temperature and visibility at 2 meters height are presented in Fig. 2 and Fig. 3.

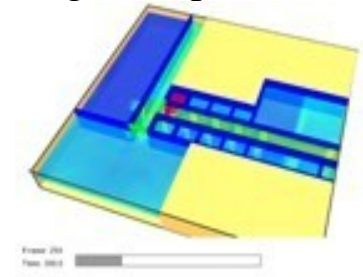

(a) time $=300$ s



(a) time $=300 \mathrm{~s}$

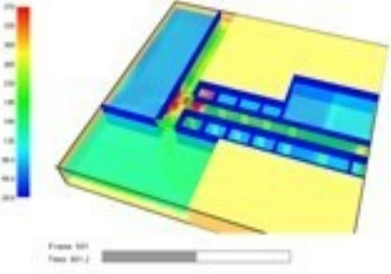

(b) time $=6005$

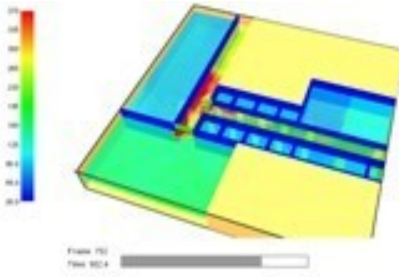

(c) time $=900 \mathrm{~s}$

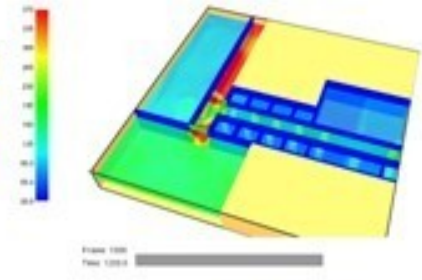

(d) $\operatorname{tim} e=1200 \mathrm{~s}$

Fig. 2. Simulation results of smoke temperature in Case 1.

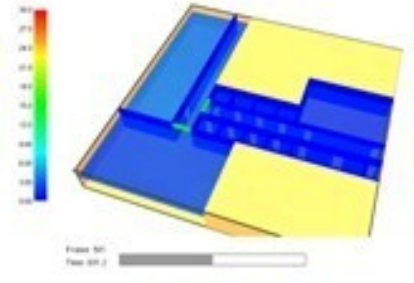

(b) time $=600 \mathrm{~s}$

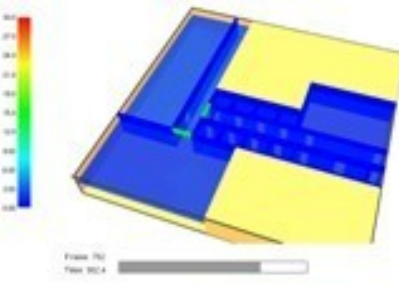

(c) time $=900 \mathrm{~s}$

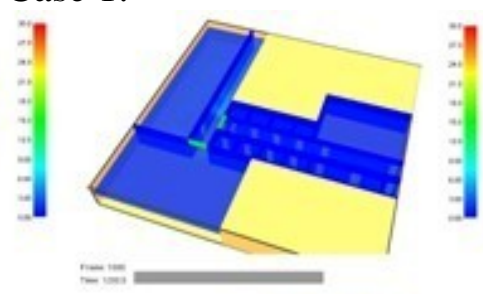

(d) time $=12005$

Fig. 3. Simulation results of visibility in Case 1.

Fig. 2 and Fig. 3 show that it is already at risk before 300 seconds after effective ignition and the narrow passageway outside the hotel is the most dangerous area where should add a new smoke outlet.

Prediction of the Required Safety Egress Times. In Eq. 1, the first two items will be obtained through the actual simulation exercises, and the evacuation action time will be simulated by Building EXODUS.

On the basis of field investigation, it was found that the customers in supermarket and net bar were almost all awake even in the night, while more than $60 \%$ guests in the hotel are sleeping in the day time. So, the simulation exercises were performed in a dormitory region with $48 \mathrm{~m}$ length (similar to the computation model). The simulation exercise results show that the mean first awareness time is equal to 54 seconds and the mean evacuation preparation time of the last people is 106 seconds.

Considering of the different fatigue level between the exercise peoples and the hotel guests in the computation model, the alarm time and the evacuation preparation time are defined as 60 seconds and 120 seconds.

The model of the evacuation simulation is similar to the model in Fig. 1 except that there has not the ignition source in evacuation model. In the evacuation model, there has a 1.4 meters width evacuating gate in net bar, a 2.0 meters width shutter door in supermarket, and a 0.9 meters width door in each room of the hotel. And there have 75 peoples in the model which including of 10 customers and 5 staffs in the supermarket, 35 peoples in net bar, and 23 hotel guests with 2 staffs in the hotel.

The result of evacuation simulation shows the evacuation action time is equal to 42 seconds.

Thus, the required safety egress time in the computation model can be calculated by Eq. 1 . 
$\mathrm{T}_{\mathrm{R}}=60+120+1.5 \times 42=243(\mathrm{~s})$

Compare with the simulation data in Table 3, there only one fire scenario, Case 5, was satisfied with the safety evacuation model in fire. In order to ensure the safety evacuation of peoples, the minimum smoke exhaust rate per smoke outlet and air flow rate per secondary tuyere are 5.56 cubic meter per second and 3.89 cubic meter per hour besides the normal sprinklers.

\section{Summary}

In the present paper, the parameters adjustment schemes of smoke control system in a complicated underground zone are carried out by numerical simulations. The main conclusions are as follows:

1) The critical smoke temperature is the major factor in predicting the available safety egress times in fire.

2) In case of a fire, increasing the smoke exhaust rate of smoke outlet and air flow rate of the secondary tuyere can offer more available safety egress times.

3) In order to ensure the safety evacuation, TR $<$ TA, the minimum smoke exhaust rate per smoke outlet and air flow rate per secondary tuyere are 5.56 and 3.89 cubic meter per second besides the normal sprinklers, which are the adjusted parameters in the new smoke control system.

4) Some specified values of smoke controlling in [7] and [8] are smaller for complicated underground zone.

\section{References}

[1] H. Xie, The assessment of fire risk on underground commercial street, Shengyang institute of aeronautical engineering, Shengyang, PR China, 2010, pp. 1-2(in Chinese)

[2] E.K. Stefopoulos, D.G. Damigos, Design of emergency ventilation system for an underground storage facility, Tunnelling and Underground Space Technology. 22(2007) 293-302.

[3] O. Vauquelin, O. Megret, Smoke extraction experiments in case of fire in a tunnel, Fire Safety Journal. 37(2002) 525-533

[4] J. Modic, Fire simulation in road tunnels, Tunnelling and Underground Space Technology. 18( 2003)525-530

[5] P. Z. Gao, S. L. Liu, W. K. Chow, N. K. Fong, Large eddy simulations for studying tunnel smoke ventilation, Tunnelling and Underground Space Technology. 19(2004)577-586

[6] S. J. Ma, Simulation study of fire smoke control in underground commercial building, Beijing University of Technology, Beijing, PR China, 2004, pp.1-6(in Chinese)

[7] “Code for fire protection design of buildings”, the Ministry of Public Security, PR China, GB50016-2006, 2006(in Chinese)

[8] “Technical specification for building smoke”, Shanghai Construction Standards, shanghai, PR China, DGJ08-88-2006, 2006(in Chinese)

[9] W. Dai, Human body’s tolerance to heat and cold, Civil Defence Realm. 6(2006) 42(in Chinese)

[10] J. D. Sime, An occupant response shelter escape time (ORSET) model, Safety Science. 38( 2001) 109-125

[11]Z. X. Xing, X. F. Zhao, W. Liu, Study on the prediction of evacuation time in public building, Proceedings of 2010 (shenyang, china) international colloquium on safety science and technology, Sept. 2010, pp.941-946 